\section{OPEN ACCESS}

Edited by:

Shannon Neville Westin

University of Texas MD Anderson Cancer Center, United States

Reviewed by:

Martina Arcieri,

University of Eastern Piedmont, Italy Patricia Benites Goncalves Silva,

German Cancer Research

Center, Germany

Olfat Ali Hammam,

Theodor Bilharz Research Institute, Egypt

*Correspondence:

Jorge Organista-Nava

joorna@gmail.com

Berenice Illades-Aguiar b.illadesaguiar@gmail.com

Specialty section:

This article was submitted to Women's Cancer,

a section of the journal

Frontiers in Oncology

Received: 01 August 2019

Accepted: 13 February 2020

Published: 11 March 2020

Citation:

Clemente-Periván SI,

Gómez-Gómez Y, Leyva-Vázquez MA

Lagunas-Martínez $A$,

Organista-Nava J and Illades-Aguiar B

(2020) Role of Oct3/4 in Cervical

Cancer Tumorigenesis.

Front. Oncol. 10:247.

doi: 10.3389/fonc.2020.00247

\title{
Role of Oct3/4 in Cervical Cancer Tumorigenesis
}

\begin{abstract}
Sayuri Itzel Clemente-Periván 1, Yazmín Gómez-Gómez ${ }^{1}$, Marco Antonio Leyva-Vázquez" Alfredo Lagunas-Martínez ${ }^{2}$, Jorge Organista-Nava ${ }^{1 *}$ and Berenice Illades-Aguiar ${ }^{1 *}$
\end{abstract}

${ }^{1}$ Laboratorio de Biomedicina Molecular, Facultad de Ciencias Químico Biológicas, Universidad Autónoma de Guerrero, Chilpancingo, Mexico, ${ }^{2}$ Centro de Investigación sobre Enfermedades Infecciosas, Instituto Nacional de Salud Pública, Cuernavaca, Mexico

Cervical cancer (CC) is the fourth most common type of cancer that affects women. Compared to other types of cancer, CC has a high mortality rate in women worldwide. Several factors contribute to the development of CC, but persistent high-risk human papillomavirus infection is the main etiologic agent associated with the development of CC. Moreover, several studies reported that alterations in the expression of transcription factors present in a small subpopulation of cells within tumors called cancer stem cells (CSCs), which contribute to the development of CC by promoting tumorigenicity and metastasis. These transcription factors affect self-renewal and maintenance of pluripotency and differentiation in stem cells. OCT3/4 belongs to the family of transcription factors with the POU domain. It consists of five exons and can be edited by alternative splicing into three main transcripts: OCT3/4A, OCT3/4B, and OCT3/4B1. The OCT3/4 expression in CSCs promotes carcinogenesis and the development of malignant tumors, and the loss of expression leads to the loss of self-renewal and proliferation and favors apoptosis. This review describes the main roles of OCT3/4 in CC and its importance in several biological processes that contribute to the development of CC and may serve as molecular targets to improve prognosis of CC.

Keywords: cervical cancer, cancer stem cells, ОСТ3/4, proliferation, self-renewal

\section{INTRODUCTION}

Cervical cancer (CC) is a worldwide public health problem. In 2018, there were an estimated 569,847 new cases and 311,365 deaths due to CC. It occupies the fourth place in women's, among all cancers with respect to incidence and mortality worldwide (1). Cervical cancer is more common in developing countries, where $85 \%$ of cases were observed, than in the rest of the world (2).

Cervical cancer is a multifactorial disease. Some of the factors associated with CC included the use of oral contraceptives for more than 5 years, multiparity, socioeconomic status, obesity, pregnancy, and sexual activity at an early age (3). Persistent human papillomavirus (HPV) infection, mainly HPV types 16 and 18 , is the most important factor, which is related to $99.7 \%$ of cervical squamous cell cancer cases worldwide (4). Although most HPV infections are transient and eliminated by the immune system (5), factors such as the immune status, coinfection, parity, and smoking can lead to a chronic high-risk (HR) HPV infection that favors the development of preneoplastic lesions (6). In addition, recent studies revealed the importance of cancer stem cells 
(CSCs) in the development of resistance, metastases, and tumorigenicity of cancer (7-9).

The CSCs and embryonic stem cells (ESCs) share similar characteristics such as self-renewal, unlimited proliferation, and the ability to maintain undifferentiated status. These characteristics are maintained by stem cell markers such as SOX2, NANOG, and OCT3/4, the latter belonging to the family of transcription factors with the POU domain (10). Recently, it has been indicated that these stem cell markers are highly expressed during the tumorigenesis process (11); however, their role in the processes that favor the development of CC remains unclear. The present mini review discusses the importance of OCT3/4 in acquisition of CSCs characteristics in CC. This mini review provides a broad view regarding OCT3/4, a marker that might be an appropriate target for therapy to improve the treatment of CC.

\section{OCT3/4 AND ITS ROLE IN CC OCT3/4 and Stem Cells}

Stem cells are cells that divide symmetrically to give rise to daughter cells for self-renewal and amplification, as well as asymmetrically to produce specific and differentiated lineages (12-14).

OCT3/4 (or POU5F1) is a transcription factor that binds as an octamer and is a key regulator of pluripotency, differentiation, and self-renewal in ESCs (15). It was first reported in 1989 (16), and its expression has been observed in ovulated oocytes, early preimplantation embryos, primitive ectoderm, the inner cell mass, ESCs, embryonic germ cells, and embryonic carcinoma cells but not in their differentiated daughters $(17,18)$.

The OCT $3 / 4$ gene is located on chromosome 6 , consists of five exons, and can be edited by alternative splicing into three main transcripts: OCT3/4A, OCT3/4B (19), and OCT3/4B1 (20), and generate four proteins: OCT3/4A, OCT3/4B-190, OCT4B-265, and OCT3/4B-164. OCT3/4A and OCT3/4B/B1 are functionally and structurally divided into an $\mathrm{N}$-terminal transcriptional activation domain, a central POU domain, and a C-terminal cell-type-specific transactivation domain (21). Additionally, new spliced variants of OCT4 have been detected, such as OCT4B2 (22), OCT4B3 (23), OCT4B4 (24), OCT4C, and OCT4C1 (25). These new variants have been identified in different cell lines; however, all showed a decrease in their expression by induction of cell differentiation, demonstrating a role similar to the previously reported variants, which are attributed to maintaining undifferentiated state in the cell $(23,24)$. However, the location of the different OCT3/4 isoforms correlated with their various functions'; unlike OCT3/4A, OCT3/4B is mainly found in the cytoplasm (26). Cauffman et al. $(27,28)$ analyzed the expression patterns of OCT $3 / 4 \mathrm{~A}$ and OCT $3 / 4 \mathrm{~B}$ during human embryogenesis in human ESCs and found that OCT3/4A had significant expression in all embryo nuclei and compact blasts, and OCT3/4B was expressed in the cytoplasm from the four-cell stage. The localization of OCT $3 / 4 \mathrm{~B}$ suggests that it may play a role in other biological functions such as stress response (29). On the other hand, the cell self-renewal characteristics of OCT $3 / 4$ can be attributed to the OCT3/4A isoform (26).

\section{OCT3/4 and CSCs}

Cancer stem cells are defined functionally as a subset of cells that display stemness characteristics, including the ability to asymmetrically divide, resulting in self-renewal of CSCs and the production of heterogeneous populations of cancer cells (30). The CSCs have been isolated in a variety of solid tumors such as breast cancer, glioblastoma, osteosarcoma, prostate cancer, ovarian cancer, gastric cancer, and lung cancer (31). The expression of OCT3/4 plays an important role in the malignant potential of tumor cells and can be detected in different types of tumors, such as human embryonal carcinomas, testicular germ cell tumors, and gliomas $(32,33)$. The transcription factors SOX2 and OCT3/4 were proposed as biomarkers for cell-type CSCs of cell lines and malignant tissues such as breast cancer $(34,35)$, human non-small cell lung cancer (11), bladder cancer, colon cancer, prostate cancer (36), and gastric cancer cells (37). Moreover, these transcription factors that confer "stemness" characteristics to the cancer cells contribute to carcinogenesis, tumor metastasis, and poor results $(38,39)$.

It was shown that CSCs that expressed OCT3/4 have characteristics that confer chemoresistance and radioresistance $(40,41)$. López et al. (40) characterized a subpopulation of cells with self-renewal capacity in four cancer-derived cell lines (HeLa, $\mathrm{SiHa}, \mathrm{CaSki}$, and C-4 I) and found expression of characteristic markers of stem cell, epithelial-mesenchymal transition (EMT), and radioresistance. These data could contribute to the improvement of therapies aimed at cancer patients and reduction in the mortality caused by this disease. It has been observed that OCT3/4 may be a therapeutic target, because the loss of OCT3/4 expression in cells leads to the loss of self-renewal and proliferation capacities, favoring the process of apoptosis CSCs (42). Therefore, conventional treatments along with therapy directed at markers of CSCs (OCT3/4) are a promising treatment option in efforts to eradicate cancer in clinical settings.

\section{Oct3/4 in CC}

High-risk HPV infection targets the cuboidal epithelial cells within the transformation zone that are considered stem cells of the cervical epithelium. The characteristics of these stem cells contribute to the development of CC because they have the capacity for self-renewal and are capable of generating diverse lineages of cancer cells [(10, 43-45); Figure 1]. It was reported that OCT3/4 can act as an oncogene and trigger cancerous stem cells $(46,47)$. Several studies were conducted both in vivo and in vitro to study the role of OCT3/4 in CC. The expression of OCT3/4 was investigated in patients with CC by immunohistochemistry, and it was high in premalignant and malignant cervical tumors (38). Similarly, OCT3/4 expression was strongly associated with poor disease-free survival and overall survival (poor prognosis) in patients with CC, which suggests that OCT3/4 expression is a possible marker for this type of cancer (48).

In samples with $\mathrm{CC}$, it was observed that the expression of OCT3/4 increases according to the degree of injury, and this expression was higher in the nucleus than in the cytoplasm (38). High-risk HPV-positive cell lines such as HeLa and CaSki have higher expression of OCT $3 / 4$ in the nucleus than in the 


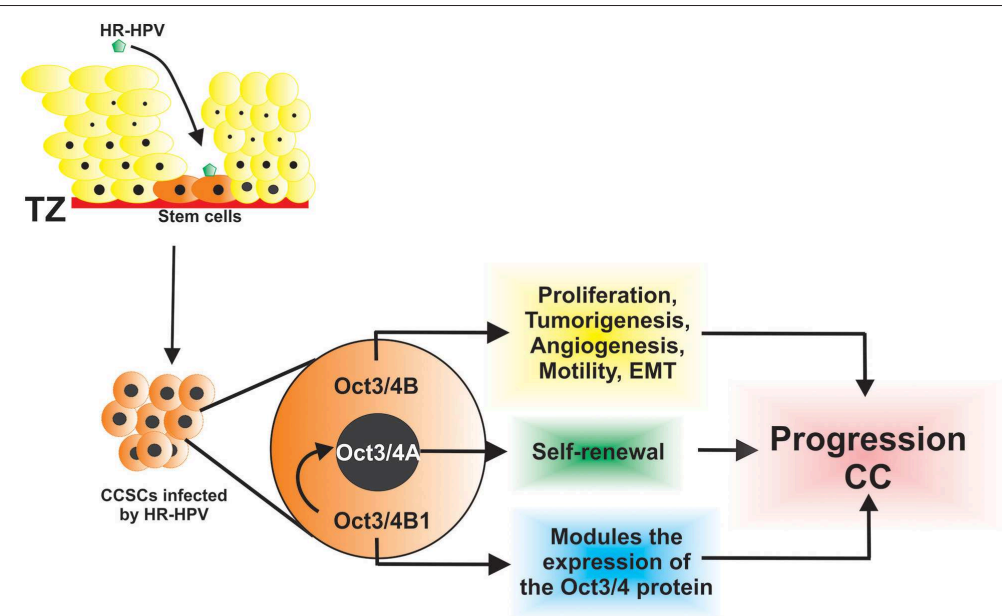

FIGURE 1 | The HR-HPV infects CSCs that express isoforms of Oct3/4 and contributes to the progression of cervical cancer through diverse, key, and biological processes.

cytoplasm, and consequently, these cell lines have higher colony formation capacity than the C-33 A cell line (HPV negative) in which OCT3/4 expression was homogeneous in the nucleus and cytoplasm (49). In addition, the active protein of OCT3/4 is mainly located in the nucleus, whereas the nonfunctional protein with respect to the maintenance of stemness characteristics is mainly located in the cytoplasm $(26,28)$. These data suggest that the HPV can initiate cervical carcinogenesis through the positive regulation of OCT3/4 (49).

On the other hand, little is known about the mechanism of epigenetic regulation on the level of expression of OCT3/4 in CC cells (49). In 2012, Liu et al. (50) observed that the inhibition of an important member of the histone deacetylase (HDAC) family, histone deacetylase 1 (HDAC1) by valproic acid, can promote the transcription of OCT3/4 in C33A cells. It has been reported that there could be an interaction between the E7 oncoprotein of HPV16 and HDAC1, thus causing the dissociation of the complex between HDAC1 and DNMT3A, leading to an increase in the expression of OCT3/4 (50). Interestingly, the inhibition of DNMT3A and HDAC1 with 5-azacitidine (inducer of DNA hypomethylation) and tricostatin A (HDAC inhibitor) leads to a negative regulation of OCT3/4 expression $(51,52)$. Likewise, it was observed that the inhibition of DNMT with 5-azacitidine leads to a decrease in the expression of OCT3/4 and the negative regulation of proliferation-associated proteins such as cyclin D1 (52). Cyclin D1 is associated with cyclin-dependent kinase 4 or 6 , and this complex phosphorylates and activates genes whose products regulate the G1/S transition of the cell cycle $(52,53)$. These data suggest that HDAC1 and DNMT3A exist in a common complex, which is associated with the OCT3/4 expression in CC cells (50).

Furthermore, the clinicopathological significance of OCT3/4 in cervical squamous cell carcinoma (CSCC) and its correlation with occurrence and prognosis were investigated using CSCC tissue and normal cervical tissue, finding that OCT3/4 expression was higher in CSCC tissue than in normal cervical tissue; in addition, the expression of OCT3/4 and SOX2 was significantly related to the Wnt signaling pathway (54). Wnt/ $\beta$ canonical signaling plays an important role in the self-renewal, pluripotency, proliferation, and determination of the cellular fate of ESCs; it was found that Wnt/ $\beta$-catenin signaling is one of the key pathways in the maintenance of CSC (e.g., in lung, colon, liver, and breast cancer) (55). Both biomarkers of ESC (SOX2 and OCT3/4) and the Wnt signal pathway ( $\beta$-catenin) are activated in CSCC (54).

Additionally, it has been reported that SOX2 and OCT3/4 stem cell biomarkers could be used to predict radioresistance in patients with locally advanced CSCC (LACSCC). Shen et al. (56) evaluated the expression of OCT3/4 and SOX2 by immunohistochemistry in two groups: the radioresistant group and a group sensitive to radiation; they showed that the expression of SOX2 and OCT3/4 was higher in the group resistant to radiation than in the sensitive group. This suggested that the expression of SOX 2 and OCT3/4 in tumor cells indicates radioresistance and is important an predictor of poor survival in patients with LACSCC (56). On the other hand, it was discovered that two pseudogenes of OCT3/4, that is, OCT3/4-pg5 and OCT3/4-pg1, are transcribed in cancer (57). OCT3/4-pg5 is transcribed in cells and cancer tissues, whereas OCT3/4-pg1 is found only in cancerous tissues at a low level (57), while Hayashi et al. (58) found that it is overexpressed in gastric cancer when compared to its normal counterpart. The transcription of these pseudogenes in cancer samples suggests that they may play a role in the regulation of OCT3/4 gene activity and carcinogenesis (57).

Previously, Mueller et al. (59) demonstrated that only OCT3/4B is present in cell lines of somatic tumors (colorectal carcinoma cells, thyroid carcinoma, cervical carcinoma, head and neck carcinoma, non-small cell lung carcinoma hepatoma, breast carcinoma, ovarian carcinoma, prostate carcinoma, neuroblastoma, glioblastoma, and melanoma) (59). Moreover, recent studies have demonstrated overexpression of OCT3/4A in patients with hepatocellular carcinoma in prostate cancer, lung 
cancer, hepatocellular carcinoma, and breast cancer and also in vivo models of prostate cancer (60-62).

To understand the biological functions of the two OCT3/4 isoforms in CC cells, $\mathrm{Li}$ et al. (46) evaluated sphere formation efficiency in stable cell lines: $\mathrm{SiHa}-\mathrm{OCT} 3 / 4 \mathrm{~A}$ and $\mathrm{SiHa}-\mathrm{OCT} 3 / 4 \mathrm{~B}$ and showed that $\mathrm{SiHa}-\mathrm{OCT} 3 / 4 \mathrm{~A}$ cells had increased sphere

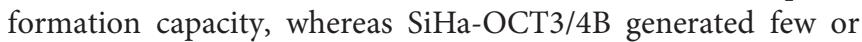
even no tumor spheres. This confirmed that OCT3/4A promoted tumor sphere formation in CC cell lines and that OCT3/4A was responsible for self-renewal of CSCs (46). In addition, overexpression of OCT3/4B in the CC SiHa cell line favors cell proliferation; tumorigenesis by inhibiting apoptosis; enhanced angiogenesis by positive regulation of CD34, VEGF, HIF- $1 \alpha$, and IL-6; tumor cell migration to the surrounding tissue through the upregulation of MMP2 and MMP9; and induction of EMT (46). Thus, both isoforms cooperate in diverse functions to regulate the progression of CC (Figure 1). Furthermore, it was observed that the reduction in the expression of OCT3/4B inhibited cell proliferation and cell migration, promoted cell apoptosis both in vitro and in vivo, and showed that OCT3/4B has functions as a novel tumor oncogene in CC, which may serve as an effective diagnostic biomarker and a potential therapeutic target in the treatment of CC (63).

\section{Oct3/4 and E6 and E7 Oncoproteins}

During HR-HPV infection, the virus binds to the receptors on the target cell surface, resulting in its internalization, and subsequently, the viral DNA is released and transported to the cell nucleus $(45,64)$. After the viral DNA is integrated, it synthesizes the E6 and E7 oncoproteins that promote proliferation for TP53 degradation by E6 and pRB degradation by E7; it has been observed that the degradation of $\mathrm{pRb}$ leads to the overexpression of OCT3/4 and that the degradation of p53 leads to an increase in the expression of NANOG $(65,66)$, and it is well known

\section{REFERENCES}

1. GLOBOCAN. GLOBOCAN (IARC). (2019). Available online at: https://gco. iarc.fr/ (accessed February 1, 2019).

2. Chuang LT, Temin S, Camacho R, Dueñas-Gonzalez A, Feldman S, Gultekin $\mathrm{M}$, et al. Management and care of women with invasive cervical cancer: American society of clinical Oncology resource-stratified clinical practice guideline. J Glob Oncol. (2016) 2:311-40. doi: 10.1200/JGO.2016.003954

3. American Cancer Society (2019). Available online at: https://www.cancer.org (accessed March 4, 2019).

4. Bruni L, Barrionuevo-Rosas L, Albero G, Serrano B, Mena M, Gómez D, et al. Human Papillomavirus and Related Diseases in the World. Summary Report. ICO/IARC Information Centre on HPV and Cancer (HPV Information Centre) (2018).

5. Zhang L, Liao H, Yang B, Geffre CP, Zhang A, Zhou A, et al. Variants of human papillomavirus type 16 predispose toward persistent infection. Int J Clin Exp Pathol. (2015) 8:8453-9.

6. Lin J, Albers AE, Qin J, Kaufmann AM. Prognostic significance of overexpressed p16INK4a in patients with cervical cancer: a meta-analysis. PLoS ONE. (2014) 9:e106384. doi: 10.1371/journal.pone.0106384

7. Krause M, Dubrovska A, Linge A, Baumann M. Cancer stem cells: radioresistance, prediction of radiotherapy outcome and specific targets for combined treatments. Adv Drug Deliv Rev. (2017) 109:63-73. doi: 10.1016/j.addr.2016.02.002 that NANOG can directly bind to the OCT3/4 gene promoter to induce its expression (67-69). Recently, it was observed that the E6 and E7 oncoproteins of HPV16 increase expression levels of a subset of stem cell marker genes, including OCT3/4, NANOG, and SOX2 both in vivo and in vitro and that cells expressing the E6 and E7 oncoprotein exhibit a greater self-renewal capacity $(70,71)$. These data suggest that the E6 and E7 oncoproteins increase the self-renewal of cancer cells.

\section{CONCLUSION}

Because CC is one of the leading causes of death in women worldwide, it is important to understand the mechanisms involved in its development and progression. The data presented here demonstrate a role for OCT3/4 in cervical carcinogenesis. The high expression of OCT3/4 was associated with cancerous cells and tissues, and it was suggested that it has the ability to promote CC. Moreover, OCT3/4 has been suggested as an important biomarker of prognosis and resistance to chemotherapy and radiotherapy in patients with CC.

\section{AUTHOR CONTRIBUTIONS}

SC-P, YG-G, and JO-N collated the references and wrote this review. AL-M, ML-V, JO-N, and BI-A reviewed and edited the manuscript.

\section{FUNDING}

The present study was supported by a grant from CONACYT, México (Investigación Científica Básica 2016; grant no. 288612). This study was supported by Universidad Autónoma de Guerrero. SC-P (CVU/Becario: 857665/627613) was a recipient of mastery fellowships from CONACYT.
8. Javed S, Sharma BK, Sood S, Sharma S, Bagga R, Bhattacharyya S, et al. Significance of CD133 positive cells in four novel HPV-16 positive cervical cancer-derived cell lines and biopsies of invasive cervical cancer. BMC Cancer. (2018) 18:357. doi: 10.1186/s12885-018-4237-5

9. Sun Q, Lesperance J, Wettersten H, Luterstein E, DeRose YS, Welm A, et al. Proapoptotic PUMA targets stem-like breast cancer cells to suppress metastasis. J Clin Investig. (2018) 128:531-44. doi: 10.1172/JCI93707

10. Organista-Nava J, Gómez-Gómez Y, Gariglio P. Embryonic stem cellspecific signature in cervical cancer. Tum Biol. (2014) 35:1727-38. doi: 10.1007/s13277-013-1321-y

11. Li X, Wang J, Xu Z, Ahmad A, Li E, Wang Y, et al. Expression of Sox2 and Oct4 and their clinical significance in human non-small-cell lung cancer. Int J Mol Sci. (2012) 13:7663-75. doi: 10.3390/ijms13067663

12. Okamoto K, Okazawa H, Okuda A, Sakai M, Muramatsu M, Hamada H. A novel octamer binding transcription factor is differentially expressed in mouse embryonic cells. Cell. (1990) 60:461-72. doi: 10.1016/0092-8674(90)90597-8

13. Rosner MH, Vigano MA, Ozato K, Timmons PM, Poirie F, Rigby PWJ, et al. A POU-domain transcription factor in early stem cells and germ cells of the mammalian embryo. Nature. (1990) 345:686-92. doi: 10.1038/345686a0

14. Schöler HR, Ruppert S, Suzuki N, Chowdhury K, Gruss P. New type of POU domain in germ line-specific protein Oct-4. Nature. (1990) 344:435-9. doi: $10.1038 / 344435 \mathrm{a} 0$

15. Lengerke C, Fehm T, Kurth R, Neubauer H, Scheble V, Müller F, et al. Expression of the embryonic stem cell marker SOX2 in early-stage 
breast carcinoma. BMC Cancer. (2011) 11:42. doi: 10.1186/1471-240711-42

16. Schöler H, Hatzopoulos AK, Balling R, Suzuki N, Gruss P. A family of octamer-specific proteins present during mouse embryogenesis: evidence for germline-specific expression of an Oct factor. EMBO J. (1989) 8:2543-50. doi: 10.1002/j.1460-2075.1989.tb08392.x

17. Solter D. Mammalian cloning: advances and limitations. Nat Rev Genet. (2000) 1:199-207. doi: 10.1038/35042066

18. Niwa H. Molecular mechanism to maintain stem cell renewal of ES cells. Cell Struct Funct. (2001) 26:137-48. doi: 10.1247/csf.26.137

19. Takeda J, Seino S, Bell GI. Human Oct3 gene family: cDNA sequences, alternative splicing, gene organization, chromosomal location, and expression at low levels in adult tissues. Nucleic Acids Res. (1992) 20:4613-20. doi: 10.1093/nar/20.17.4613

20. Atlasi Y, Mowla SJ, Ziaee SAM, Gokhale PJ, Andrews PW. OCT4 spliced variants are differentially expressed in human pluripotent and nonpluripotent cells. Stem Cells. (2008) 26:3068-74. doi: 10.1634/stemcells.2008-0530

21. Wang X, Dai J. Concise review: isoforms of OCT4 contribute to the confusing diversity in stem cell biology. Stem Cells. (2010) 28:885-93. doi: 10.1002/stem.419

22. Poursani EM, Mehravar M, Soltani BM, Mowla SJ. OCT4B2, a novel alternative spliced variant of OCT4, is significantly upregulated under heatstress condition and downregulated in differentiated cells. Tum Biol. (2017) 39:1010428317724280. doi: 10.1177/1010428317724280

23. Mowla SJ, Poursani E, Mehravar M, Trosko JE. Discovery of a novel variant of OCT4, OCT4B3. J Genes Cells. (2016) 2:32. doi: 10.15562/gnc.38

24. Poursani EM, Mehravar M, Soltani BM, Mowla SJ. Novel variant of OCT4B4 is differentially expressed in human embryonic stem and embryonic carcinoma cells. Gene. (2017) 627:369-72. doi: 10.1016/j.gene.2017.06.032

25. Malakootian M, Azad FM, Naeli P, Pakzad M, Fouani Y, Bajgan ET, et al. Novel spliced variants of OCT4, OCT4C and OCT4C1, with distinct expression patterns and functions in pluripotent and tumor cell lines. Eur J Cell Biol. (2017) 96:347-55. doi: 10.1016/j.ejcb.2017.03.009

26. Lee J, Kim HK, Rho J-Y, Han Y-M, Kim J. The human OCT-4 isoforms differ in their ability to confer self-renewal. J Biol Chem. (2006) 281:33554-65. doi: 10.1074/jbc.M603937200

27. Cauffman G, Van de Velde H, Liebaers I, Van Steirteghem A. Oct-4 mRNA and protein expression during human preimplantation development. MHR: Basic Sci Reprod Med. (2004) 11:173-81. doi: 10.1093/molehr/gah155

28. Cauffman G, Liebaers I, Van Steirteghem A, Van de Velde H. POU5F1 isoforms show different expression patterns in human embryonic stem cells and preimplantation embryos. Stem Cells. (2006) 24:2685-91. doi: 10.1634/stemcells.2005-0611

29. Wang X, Zhao Y, Xiao Z, Chen B, Wei Z, Wang B, et al. Alternative translation of OCT4 by an internal ribosome entry site and its novel function in stress response. Stem Cells. (2009) 27:1265-75. doi: 10.1002/stem.58

30. Baillie R, Tan ST, Itinteang T. Cancer stem cells in oral cavity squamous cell carcinoma: a review. Front Oncol. (2017) 7:112. doi: 10.3389/fonc.2017.00112

31. Visvader JE, Lindeman GJ. Cancer stem cells in solid tumours: accumulating evidence and unresolved questions. Nat Rev Cancer. (2008) 8:755-68. doi: $10.1038 / \mathrm{nrc} 2499$

32. Ikushima $H$, Todo $T$, Ino $Y$, Takahashi $M$, Saito $N$, Miyazawa $K$, et al. Glioma-initiating cells retain their tumorigenicity through integration of the Sox axis and Oct4 protein. J Biol Chem. (2011) 286:41434-41. doi: 10.1074/jbc.M111.300863

33. Sung B, Do H-J, Park S-W, Huh S-H, Oh J-H, Chung H-J, et al. Regulation of OCT4 gene expression by liver receptor homolog-1 in human embryonic carcinoma cells. Biochem Biophys Res Commun. (2012) 427:31520. doi: 10.1016/j.bbrc.2012.09.049

34. Ezeh UI, Turek PJ, Reijo RA, Clark AT. Human embryonic stem cell genes OCT4, NANOG, STELLAR, and GDF3 are expressed in both seminoma and breast carcinoma. Cancer. (2005) 104:2255-65. doi: 10.1002/cncr. 21432

35. Leis O, Eguiara A, Lopez-Arribillaga E, Alberdi MJ, Hernandez-Garcia S, Elorriaga $\mathrm{K}$, et al. Sox 2 expression in breast tumours and activation in breast cancer stem cells. Oncogene. (2011) 31:1354. doi: 10.1038/onc.2011.338

36. Amini S, Fathi F, Mobalegi J, Sofimajidpour H, Ghadimi T. The expressions of stem cell markers: Oct4, nanog, Sox2, nucleostemin, Bmi, Zfx, Tcl1, Tbx3,
Dppa4, and esrrb in bladder, colon, and prostate cancer, and certain cancer cell lines. Anatomy Cell Biol. (2014) 47:1-11. doi: 10.5115/acb.2014.47.1.1

37. Chen B, Zhu Z, Li L, Ye W, Zeng J, Gao J, et al. Effect of overexpression of Oct4 and Sox 2 genes on the biological and oncological characteristics of gastric cancer cells. OncoTargets Ther. (2019) 12:4667. doi: 10.2147/OTT.S209734

38. Wang Y-D, Cai N, Wu X, Cao H, Xie L, Zheng P. OCT4 promotes tumorigenesis and inhibits apoptosis of cervical cancer cells by miR-125b/BAK1 pathway. Cell Death Dis. (2013) 4:e760. doi: $10.1038 /$ cddis.2013.272

39. Lathia JD, Liu H. Overview of cancer stem cells and stemness for community oncologists. Target Oncol. (2017) 12:387-99. doi: 10.1007/s11523-0170508-3

40. López J, Poitevin A, Mendoza-Martínez V, Pérez-Plasencia C, GarcíaCarrancá A. Cancer-initiating cells derived from established cervical cell lines exhibit stem-cell markers and increased radioresistance. BMC Cancer. (2012) 12:48. doi: 10.1186/1471-2407-12-48

41. Mohiuddin IS, Wei S-J, Kang MH. Role of OCT4 in cancer stem-like cells and chemotherapy resistance. Biochim Biophys Acta Mol Basis Dis. (2019) 1866:165432. doi: 10.1016/j.bbadis.2019.03.005

42. Hu T, Liu S, Breiter DR, Wang F, Tang Y, Sun S. Octamer 4 small interfering RNA results in cancer stem cell-like cell apoptosis. Cancer Res. (2008) 68:6533-40. doi: 10.1158/0008-5472.CAN-07-6642

43. Ortiz-Sánchez E, Santiago-López L, Cruz-Domínguez VB, Toledo-Guzmán ME, Hernández-Cueto D, Muñiz-Hernández S, et al. Characterization of cervical cancer stem cell-like cells: phenotyping, stemness, and human papilloma virus co-receptor expression. Oncotarget. (2016) 7:31943. doi: 10.18632/oncotarget.8218

44. Mendoza-Almanza G, Ortíz-Sánchez E, Rocha-Zavaleta L, Rivas-Santiago C, Esparza-Ibarra E, Olmos J. Cervical cancer stem cells and other leading factors associated with cervical cancer development. Oncol Lett. (2019) 18:3423. doi: $10.3892 /$ ol.2019.10718

45. Organista-Nava J, Gómez-Gómez Y, Garibay-Cerdenares OL, LeyvaVázquez MA, Illades-Aguiar B. Cervical cancer stem cell associated genes: prognostic implications in cervical cancer. Oncol Lett. (2019) 18:7-14. doi: 10.3892/ol.2019.10307

46. Li S-W, Wu X-L, Dong C-L, Xie X-Y, Wu J-F, Zhang X. The differential expression of OCT4 isoforms in cervical carcinoma. PLoS ONE. (2015) 10:e0118033. doi: 10.1371/journal.pone.0118033

47. Saha SK, Jeong Y, Cho S, Cho S-G. Systematic expression alteration analysis of master reprogramming factor OCT4 and its three pseudogenes in human cancer and their prognostic outcomes. Sci Rep. (2018) 8:1-19. doi: 10.1038/s41598-018-33094-7

48. Kim BW, Cho H, Choi CH, Ylaya K, Chung J-Y, Kim J-H, et al. Clinical significance of OCT4 and SOX2 protein expression in cervical cancer. BMC Cancer. (2015) 15:1015. doi: 10.1186/s12885-015-2015-1

49. Liu D, Zhou P, Zhang L, Wu G, Zheng Y, He F. Differential expression of Oct4 in HPV-positive and HPV-negative cervical cancer cells is not regulated by DNA methyltransferase 3A. Tum Biol. (2011) 32:941-50. doi: 10.1007/s13277-011-0196-Z

50. Liu D, Zhou P, Zhang L, Gong W, Huang G, Zheng Y, et al. HDAC1/DNMT3A-containing complex is associated with suppression of Oct4 in cervical cancer cells. Biochemistry. (2012) 77:934-40. doi: 10.1134/S0006297912080159

51. Cai M-H, Xu X-G, Yan S-L, Sun Z, Ying Y, Wang B-K, et al. Depletion of HDAC1, 7 and 8 by histone deacetylase inhibition confers elimination of pancreatic cancer stem cells in combination with gemcitabine. Sci Rep. (2018) 8:1-11. doi: 10.1038/s41598-018-20004-0

52. Lu Y, Qu H, Qi D, Xu W, Liu S, Jin X, et al. OCT4 maintains self-renewal and reverses senescence in human hair follicle mesenchymal stem cells through the downregulation of p21 by DNA methyltransferases. Stem Cell Res Ther. (2019) 10:1-16. doi: 10.1186/s13287-018-1120-x

53. Sherr CJ, Roberts JM. CDK inhibitors: positive and negative regulators of G1-phase progression. Genes Dev. (1999) 13:1501-12. doi: 10.1101/gad.13. 12.1501

54. Ji J, Wei X, Wang Y. Embryonic stem cell markers Sox-2 and OCT4 expression and their correlation with WNT signal pathway in cervical squamous cell carcinoma. Int J Clin Exp Pathol. (2014) 7:2470-6. Available online at: http:// www.ijcep.com/files/ijcep0000133.pdf 
55. Holland JD, Klaus A, Garratt AN, Birchmeier W. Wnt signaling in stem and cancer stem cells. Curr Opin Cell Biol. (2013) 25:254-64. doi: 10.1016/j.ceb.2013.01.004

56. Shen L, Huang X, Xie X, Su J, Yuan J, Chen X. High expression of SOX2 and OCT4 indicates radiation resistance and an independent negative prognosis in cervical squamous cell carcinoma. J Histochem Cytochem. (2014) 62:499-509. doi: $10.1369 / 0022155414532654$

57. Suo G, Han J, Wang X, Zhang J, Zhao Y, Zhao Y, et al. Oct4 pseudogenes are transcribed in cancers. Biochem Biophys Res Commun. (2005) 337:1047-51. doi: 10.1016/j.bbrc.2005.09.157

58. Hayashi H, Arao T, Togashi Y, Kato H, Fujita Y, De Velasco M, et al. The OCT4 pseudogene POU5F1B is amplified and promotes an aggressive phenotype in gastric cancer. Oncogene. (2015) 34:199-208. doi: 10.1038/onc.2013.547

59. Mueller T, Luetzkendorf J, Nerger K, Schmoll H-J, Mueller LP. Analysis of OCT4 expression in an extended panel of human tumor cell lines from multiple entities and in human mesenchymal stem cells. Cell Mol Life Sci. (2008) 66:495. doi: 10.1007/s00018-008-8623-Z

60. Huang P, Qiu J, Li B, Hong J, Lu C, Wang L, et al. Role of Sox2 and Oct4 in predicting survival of hepatocellular carcinoma patients after hepatectomy. Clin Biochem. (2011) 44:582-9. doi: 10.1016/j.clinbiochem.2011.02.012

61. De Resende MF, Chinen LTD, Vieira S, Jampietro J, Da Fonseca FP, Vassallo J, et al. Prognostication of OCT4 isoform expression in prostate cancer. Tum Biol. (2013) 34:2665-73. doi: 10.1007/s13277-013-0817-9

62. Zhou Y, Chen X, Kang B, She S, Zhang X, Chen C, et al. Endogenous authentic OCT4A proteins directly regulate FOS/AP-1 transcription in somatic cancer cells. Cell Death Dis. (2018) 9:585. doi: 10.1038/s41419-018-0606-x

63. Yu J, Zhang J, Zhou L, Li H, Deng ZQ, Meng B. The octamerbinding transcription factor 4 (OCT4) pseudogene, POU domain class 5 transcription factor $1 \mathrm{~B}$ (POU5F1B), is upregulated in cervical cancer and down-regulation inhibits cell proliferation and migration and induces apoptosis in cervical cancer cell lines. Med Sci Monitor. (2019) 25:1204-13. doi: 10.12659/MSM.912109

64. Aksoy P, Gottschalk EY, Meneses PI. HPV entry into cells. Mutat Res Rev Mutat Res. (2017) 772:13-22. doi: 10.1016/j.mrrev.2016.09.004

65. Lin T, Chao C, Saito S, Mazur SJ, Murphy ME, Appella E, et al. (2005). p53 induces differentiation of mouse embryonic stem cells by suppressing nanog expression. Nat Cell Biol. 7:165-71. doi: 10.1038/ncb1211
66. Kareta MS, Gorges LL, Hafeez S, Benayoun BA, Marro S, Zmoos A-F, et al. Inhibition of pluripotency networks by the $\mathrm{Rb}$ tumor suppressor restricts reprogramming and tumorigenesis. Cell Stem Cell. (2015) 16:39-50. doi: $10.1016 /$ j.stem.2014.10.019

67. Chambers I, Colby D, Robertson M, Nichols J, Lee S, Tweedie $\mathrm{S}$, et al. Functional expression cloning of nanog, a pluripotency sustaining factor in embryonic stem cells. Cell. (2003) 113:643-55. doi: 10.1016/S0092-8674(03)00392-1

68. Loh Y-H, Wu Q, Chew J-L, Vega VB, Zhang W, Chen X, et al. The Oct4 and nanog transcription network regulates pluripotency in mouse embryonic stem cells. Nat Genet. (2006) 38:431-40. doi: 10.1038/ng1760

69. Heurtier V, Owens N, Gonzalez I, Mueller F, Proux C, Mornico D, et al. The molecular logic of nanog-induced self-renewal in mouse embryonic stem cells. Nat Commun. (2019) 10:1109. doi: 10.1038/s41467-019-09041-Z

70. Organista-Nava J, Gómez-Gómez Y, Ocadiz-Delgado R, García-Villa E, Bonilla-Delgado J, Lagunas-Martínez A, et al. The HPV16 E7 oncoprotein increases the expression of Oct3/4 and stemness-related genes and augments cell self-renewal. Virology. (2016) 499:230-42. doi: 10.1016/j.virol.2016. 09.020

71. Tyagi A, Vishnoi K, Mahata S, Verma G, Srivastava Y, Masaldan S, et al. Cervical cancer stem cells selectively overexpress HPV oncoprotein E6 that controls stemness and self-renewal through upregulation of HES1. Clin Cancer Res. (2016) 22:4170-84. doi: 10.1158/1078-0432.CCR15-2574

Conflict of Interest: The authors declare that the research was conducted in the absence of any commercial or financial relationships that could be construed as a potential conflict of interest.

Copyright (C) 2020 Clemente-Periván, Gómez-Gómez, Leyva-Vázquez, LagunasMartinez, Organista-Nava and Illades-Aguiar. This is an open-access article distributed under the terms of the Creative Commons Attribution License (CC BY). The use, distribution or reproduction in other forums is permitted, provided the original author(s) and the copyright owner(s) are credited and that the original publication in this journal is cited, in accordance with accepted academic practice. No use, distribution or reproduction is permitted which does not comply with these terms. 